\title{
Estimation of Serum Uric Acid in Cases of Hyperuricaemia and Gout
}

\author{
Pokhrel K, ${ }^{1}$ Yadav BK, ${ }^{2}$ Jha B, ${ }^{2}$ Parajuli K, ${ }^{3}$ Pokharel $\mathrm{RK}^{4}$ \\ 'National College for Advanced Learning, Lainchour, Kathmandu, Nepal, ${ }^{2}$ Institute of Medicine, Maharajgunj, ${ }^{3}$ Dept. \\ of Orthopaedics, TUTH Maharajgunj, Kathmandu, Nepal ${ }^{4}$
}

\section{ABSTRACT}

Introduction: Gout is crystal deposit arthritis and is an ancient disease. The biologic precursor to gout is hyperuricaemia. The prevalence of hyperuricaemia and gout has an increasing trend all over the world including the developing countries. The purpose of this study is to estimate serum uric acid level in hyperuricaemic and gout patients attending a medical college hospital.

Methods: A consecutive 150 hyperuricaemics and 150 gout patients attending Tribhuwan University Teaching Hospital from June to September 2005 were included in this study. The serum uric acid level was measured by the enzymatic (PAP- Uricase) method. The patients with acute gout were interviewed and relevant information was obtained.

Results: Males comprised 84 \% of gout cases. Hyperuricaemia was common in both sexes. The mean age for gout was 47.49 and 56.65 years in males and females respectively. The mean age for the first gout attack was $42.1 \pm 14.0$ years. Family history was positive in $22 \%$ of cases. The overall mean serum uric acid level in hyperuricaemics was $7.2 \pm 0.7 \mathrm{mg} / \mathrm{dL}$ and $8.4 \pm 1.1 \mathrm{mg} / \mathrm{dL}$ in acute gout ( $p$ 0.0001). The mean serum uric acid level was significantly ( $p$ 0.0001) high among males both at the asymptomatic phase and at acute gout. Gout was more common in non-vegetarians (95\%) and alcoholics $(65.3 \%)$. Serum uric acid level was inversely related with the amount of daily water intake (p 0.0001).

Conclusions: Serum uric acid level is significantly high among the male gouty arthritic patients. However, it is also high among asymptomatic hyperuricaemic cases of both sexes.

Keywords: asymptomatic hyperuricaemia, gout, serum uric acid level

\section{INTRODUCTION}

Gout is the commonest type of crystal deposit arthritis and is an ancient disease. ${ }^{1-6}$ The biologic precursor to gout is hyperuricaemia. ${ }^{7,8}$ Hyperuricaemia is intricately linked with the metabolic syndrome. ${ }^{9-14}$ The prevalence of hyperuricaemia and gout shown an increasing trend all over the world including in developing countries, ${ }^{15-20}$ and the reasons include dietary habits, increasing longevity, sub-clinical renal impairment, and the increased use of drugs causing hyperuricaemia, particularly diuretics. ${ }^{21-26}$ Genetic predisposition and environmental factors are also responsible for hyperuricaemia. ${ }^{27-29}$ Gout is considered to be primarily a male disease, but there is a more equal sex distribution among elderly patients. ${ }^{3,18,19,30}$

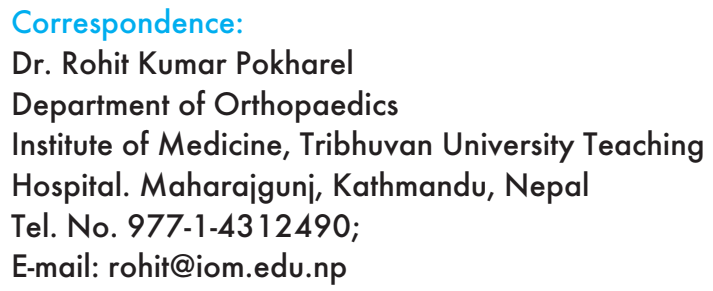

E-mail: rohit@iom.edu.np 
Pokharel et al. Estimation of Serum Uric Acid in Cases of Hyperuricaemia and Gout

The prevalence of gout in Nepal and in the developing world is less studied than in the developed world. ${ }^{17,20}$ The aim of this study is to estimate serum uric acid level in hyperuricaemics and gouty arthritis cases in the Nepalese community and its relation with dietary habits, volume of water consumption and familial predisposition.

\section{METHODS}

The study was carried out at Tribhuvan University Teaching Hospital (TUTH) Department of Biochemistry from June to September, 2005. The diagnosis of acute gouty arthritis and hyperuricaemia was made by clinicians from different departments, mainly from the departments of Orthopaedics and Internal Medicine, TUTH on a clinical basis. 300 consecutive patients, 150 gouty arthritic and 150 hyperuricaemics with no acute attack of gout coming for serum uric acid level estimation were included in the study. The patients presenting with acute bouts of gout were personally interviewed and the following information was collected - gender, age, family history, age of onset of gout, food, alcohol and water drinking habits. Cases with clinically diagnosed co-morbid conditions like renal diseases, diabetes mellitus and heart diseases were excluded from the study.

The estimation of serum uric acid was performed using the Uricase method (Human $\mathrm{GmbH}$, Germany). The reference range was $3.5-7.0 \mathrm{mg} / \mathrm{dL}$ in males and 2.6 $6.0 \mathrm{mg} / \mathrm{dL}$ in females. Hyperuricaemia was defined as a SUA level of more than $7.0 \mathrm{mg} / \mathrm{dL}$ in males and of more than $6.0 \mathrm{mg} / \mathrm{dL}$ in females. ${ }^{17,18,24,33}$ The findings were statistically analyzed. The significance of the difference in serum uric acid level between hyperuricaemic and gouty arthritic cases was analyzed by Student's Chisquare test at $95 \%$ of confidence interval.

Verbal consent was taken from each subjects of acute gouty arthritis, and the study was approved by the institutional ethic review board of the institute.

\section{RESULTS}

\section{Age and sex distribution}

Out of 300 cases, $69 \%$ (207) were males and the remaining $31 \%$ (93) were females. The age range among asymptomatic hyperuricaemics was 20 to 89 years (mean age $48.2 \pm 14.4$ years) and that of gouty arthritis cases was 22 to 86 years (mean age $48.6 \pm$ 15.3 years) respectively. The subjects were classified into 7 age groups, and the $40-49$ years age group had the highest frequency of patients in both asymptomatic hyperuricaemia and acute gout $(32.6 \%)$.
Amongst the 67 asymptomatic hyperuricaemic females, $76.2 \%$ (51) were of $\geq 40$ years while in the gouty arthritis group, $83.3 \%(20 / 24)$ were aged $\geq$ 40 years. Similarly, among males, $68.7 \%$ (57/83) of hyperuricaemic and $71.4 \%(90 / 126)$ of acute gouty arthritis cases were of more than 40 years of age. The male to female ratio among the asymptomatic hyperuricaemia group was 1.24:1 while the ratio was much higher in acute gout, 5.25: 1. The male to female ratio among patients with gout was 9:1 in the less than 40 years age group, and 4.5:1 in the more than 40 years age group (Table 1). Although there is a male predominance, this gender predominance is not statistically significant.

Table 1: Age distribution of the cases

\begin{tabular}{lllllll}
\hline Age & \multicolumn{2}{l}{$\begin{array}{l}\text { Asymptomatic } \\
\text { hyperuricaemia }\end{array}$} & \multicolumn{3}{l}{ Acute gouty arthritis } \\
group & Female & Male & Total & Female & Male & Total \\
\hline $20-29$ & 6 & 7 & 13 & 1 & 16 & 17 \\
$30-39$ & 10 & 19 & 29 & 3 & 20 & 23 \\
$40-49$ & 24 & 25 & 49 & 4 & 45 & 49 \\
$50-59$ & 15 & 14 & 29 & 6 & 17 & 23 \\
$60-69$ & 3 & 9 & 12 & 2 & 16 & 18 \\
$70-79$ & 7 & 7 & 14 & 7 & 10 & 17 \\
$80-89$ & 2 & 2 & 4 & 1 & 2 & 3 \\
Iotal & 67 & 83 & 150 & 24 & 126 & 150 \\
\hline
\end{tabular}

The onset of gout ranged from the third to the ninth decades of life. The mean age of the first episode of gout was $42.1 \pm 14.0$ years; it was $41.2 \pm 13.0$ years among the male patients and $44.5 \pm 12$ years among the female patients. The frequency of patients who had had their first gouty attack was highest $(32.7 \%)$ among the $40-49$ years age group. Young patients with gout, with the onset before age 30 , constituted $21.3 \%$. The first attack frequently occurred between the fourth and sixth decades of life (63.3\%). However, there was no correlation with the level of SUA and the age of onset of gout.

\section{Familial predisposition}

Out of 150 cases of acute gouty arthritis, 33 (22 \%) patients had a positive family history of acute gout and the rest of the cases were not having any family history.

\section{Serum uric acid (SUA) level}

Overall the mean SUA level in asymptomatic hyperuricaemics was $7.2 \pm 0.7 \mathrm{mg} / \mathrm{dL}$ and it was 8.4 $\pm 1.1 \mathrm{mg} / \mathrm{dL}$ in acute gout cases (p 0.0001). Among females, the mean SUA level was $6.7 \pm 0.6 \mathrm{mg} / \mathrm{dL}$ in hyperuricaemics and $8.0 \pm 1.3 \mathrm{mg} / \mathrm{dL}$ in acute gout cases (p 0.0001), while it was $7.6 \pm 0.5 \mathrm{mg} / \mathrm{dL}$ and $8.5 \pm 1.0 \mathrm{mg} / \mathrm{dL}$ in hyperuricaemics and acute gout 
cases ( $p$ value 0.0000) respectively in males. This difference in the SUA level at the asymptomatic and the gout stage was statistically significant. There were 9 (6\%) patients who had a normal SUA level although they had an acute attack of gout. Eleven (7\%) cases had the SUA level $>10 \mathrm{mg} / \mathrm{dL}$ (Table 2).

Table 2: Serum uric acid levels in asymptomatic hyperuricaemics and gout cases

\begin{tabular}{lcccccc}
\hline $\begin{array}{l}\text { SUA level } \\
\text { (mg / dL) }\end{array}$ & \multicolumn{2}{c}{$\begin{array}{c}\text { Asymptomatic } \\
\text { hyperuricaemia }\end{array}$} & \multicolumn{4}{c}{$\begin{array}{c}\text { Acute gouty } \\
\text { arthritis }\end{array}$} \\
& Female & Male & Total & Female & Male & Total \\
\hline $5.0-5.9$ & 0 & 0 & 0 & 5 & 0 & 5 \\
\hline $6.0-6.9$ & 49 & 0 & 49 & 0 & 4 & 4 \\
\hline $7.0-7.9$ & 15 & 63 & 78 & 5 & 32 & 37 \\
\hline $8.0-8.9$ & 2 & 17 & 19 & 8 & 57 & 65 \\
\hline $9.0-9.9$ & 1 & 3 & 4 & 5 & 23 & 28 \\
\hline $10.0-10.9$ & 0 & 0 & 0 & 1 & 8 & 9 \\
\hline $11.0-11.9$ & 0 & 0 & 0 & 0 & 2 & 2 \\
\hline Total & 67 & 83 & 150 & 24 & 126 & 150 \\
\hline
\end{tabular}

The age adjusted mean SUA was always higher in acute gout cases than among the asymptomatic hyperuricaemia group. Similarly, it was higher among the male hyperuricaemic cases compared to female cases (Figure 1). However, the age adjusted mean SUA level was closer among male and female gouty arthritic cases. The age adjusted mean SUA for male and female was almost the same for the $20-29$ and the $50-59$ years age group; it was rather higher among females of 80 - 90 years of age (Figure 2).

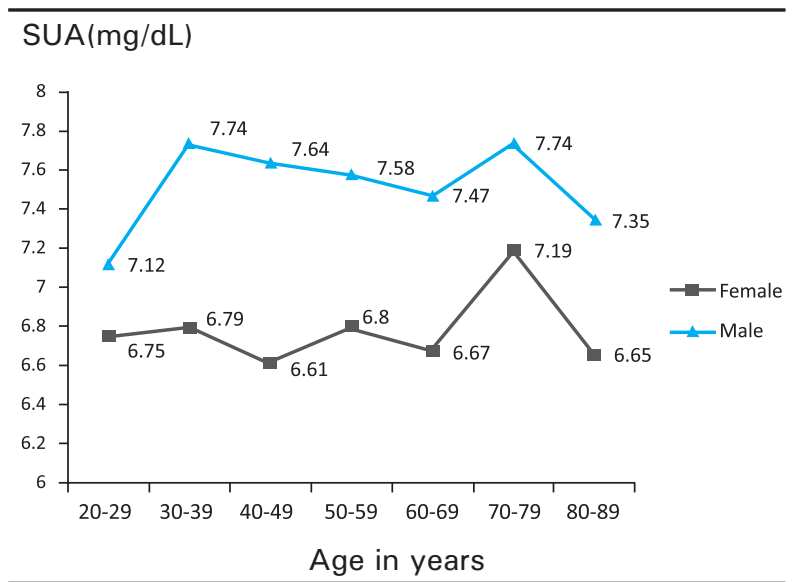

Figure 1. Age adjusted serum uric acid level among hyperuricaemic males and females

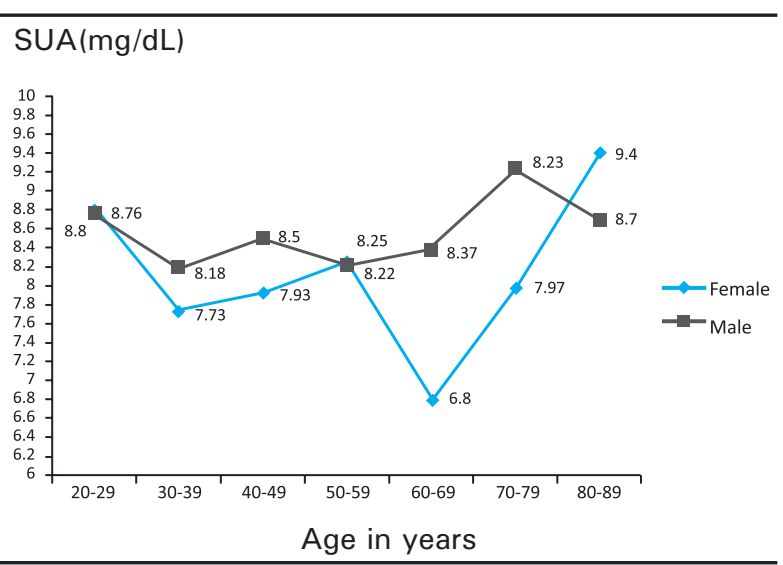

Figure 2. Age adjusted serum uric acid level among gouty arthritic males and females

Food habit, gout and serum uric acid level

Only 8 out of 150 patients $(5.3 \%)$ were either vegetarians or had not consumed meat and other meat products for more than five years. The ratio of nonvegetarians to vegetarians was $17.75: 1$ suggesting that most of the cases took meat and meat products. The mean SUA levels among the vegetarians and nonvegetarians were $8.3 \pm 1.1 \mathrm{mg} / \mathrm{dL}$ and $8.4 \pm 1.4 \mathrm{mg} /$ $\mathrm{dL}$ respectively (Table 3 ).

Table 3: Food habit and serum uric acid level

\begin{tabular}{|c|c|c|c|c|}
\hline Response & Female & Male & Total & $\begin{array}{l}\text { Mean } \\
\text { SUA } \\
(\mathrm{mg} / \mathrm{dL})\end{array}$ \\
\hline Vegetarian & $\begin{array}{l}1 \\
(4.2 \%)\end{array}$ & $\begin{array}{l}7 \\
(5.6 \%)\end{array}$ & $\begin{array}{l}8 \\
5.3 \%)\end{array}$ & 8.3 \\
\hline $\begin{array}{l}\text { Non- } \\
\text { vegetarian }\end{array}$ & $\begin{array}{l}23 \\
(95.8 \%)\end{array}$ & $\begin{array}{l}119 \\
(94.4 \\
\%)\end{array}$ & $\begin{array}{l}142 \\
(94.7 \%)\end{array}$ & 8.4 \\
\hline
\end{tabular}

Amount of water intake and level of Serum Uric Acid (SUA)

There were $20(13.3 \%)$ cases who used to take less than 1 liter of water in a day and had a mean SUA level was $9.2 \pm 0.9 \mathrm{mg} / \mathrm{dL}$. Similarly, there were $73(48.7$ $\%)$ cases taking 1 - 2 liters, 48 (32\%) cases taking 2 - 3 liters and $9(6 \%)$ cases who took more than 3 liters of water in a day and had a mean SUA level of $8.5 \pm 0.8 \mathrm{mg} / \mathrm{dL}, 8.1 \pm 1.2 \mathrm{mg} / \mathrm{dL}$ and $7.2 \pm 0.7$ $\mathrm{mg} / \mathrm{dL}$ respectively (Table 4 ). The inverse relation of the amount of daily water intake and SUA levels was statistically highly significant ( $p-0.0000)$. 
Pokharel et al. Estimation of Serum Uric Acid in Cases of Hyperuricaemia and Gout

Table 4: Amount of water intake and serum uric acid level

\begin{tabular}{lcccc}
\hline Water Intake & Female & Male & Total & Mean SUA (mg/dL) \\
\hline$<1$ liter / day & $6(25.0 \%)$ & $14(11.10 \%)$ & $20(13.30 \%)$ & 9.2 \\
$1-2$ liters / day & $8(33.30 \%)$ & $65(51.60 \%)$ & $73(48.70 \%)$ & 8.5 \\
$2-3$ liters / day & $9(37.50 \%)$ & $39(30.90 \%)$ & $48(32.00 \%)$ & 8.1 \\
$>3$ liters / day & $1(4.20 \%)$ & $8(6.40 \%)$ & $9(6.00 \%)$ & 7.2 \\
\hline
\end{tabular}

\section{Alcohol intake and gout}

Cases with acute gout were asked about their alcohol consumption habit. Among them, none of the 24 female cases took alcohol. Out of 126 male patients, 28 never drank alcohol, 30 did so occasionally, 49 took it often and the remaining 19 used to take alcohol regularly. The study shows that 52 cases $(34.7 \%)$ with acute gout did not take alcohol and 98 cases $(65.3 \%)$ used to take alcohol. It was difficult to get adequate information on the frequency, type and amount of alcohol consumption.

\section{DISCUSSION}

Multiple joint pain or generalized body ache is often self-diagnosed and said to be due to a rise in serum uric acid level 19. We analyzed serum uric acid level in 300 subjects, half of them with clinical features of acute gout and the other half of which was asymptomatic. In the study, asymptomatic hyperuricaemia was almost equal in both the sexes (M: F - 1.24:1) with the highest frequency in the $40-49$ years age group. However, the male to female ratio was significantly different among gouty arthritis cases (M : F - 5.25:1) and 16 $\%$ of the gout cases were females. Among males, the highest frequency of gout was in the $40-49$ years age group, and among females, in the 50 - 59 years age group. The M:F ratio was 9:1 in the less than 40 years age group, and 4.5:1 in the more than 40 years age group. In a hospital based study done in South India, the male to female ratio of acute gout cases was 15.8:1.20 In previous studies conducted in American 6 , African 17, Chinese ${ }^{18,26}$ and Japanese populations 19 , both hyperuricaemia and gout were significantly higher among males. Compared to those studies done in African and Asian females, The Nepalese females are relatively more hyperuricaemic and are more prone to develop gout. This difference might be because of the early menopause among Nepalese females (unpublished data, study done by Giri Kanti, Backstrom Torbjorn, Ohlin Hellen, July 2001, ISBN: 99933-59-00-9) or it might be because of the smaller sample size of our hospital based population. The majority of the serum uric acid content is contributed by endogenous production. It has been clear that postmenopausal females have a tendency of equalizing the male : female ratio partly because of inhibition of estrogen secretion. The serum composition of uric acid increases in females after they achieve menopause. ${ }^{35}$
An increase in the age tends to increase the serum uric acid level. The increase in age leads to decreased urine output resulting in hyperuricaemia. Diabetes mellitus, hypertension, cardiovascular disorders, use of diuretics, and renal impairment are quite common in the aged population and are all positively associated with hyperuricaemia. ${ }^{3,9-13,26}$ Diagnosed cases of renal failure were excluded from this study. However, sub-clinical undiagnosed cases with underlying risk factors were associated in the cases and were not ruled out.

The mean age of onset of gouty arthritis has been found varying from one place to the other. In this study, the mean age of the first episode of gout was 42.1 \pm 14.0 years $(41.2 \pm 13.0$ years in males and 44.5 \pm 12 years in females). It was 40.02 years in South Indians (39.27 years in males and 45.33 in females $)^{20}$ and, $41.6 \pm 14.7$ years among Taiwanese patients. The first episode of gout among them $<30$ years young Taiwanese patients was $25 \%$. ${ }^{29}$ The mean age of onset of acute gout was 49.5 years, relatively late, in the Japanese. ${ }^{30}$ In Framingham's study, it was found to be 48.7 years. ${ }^{32}$ Both the Caucasians and nonCaucasians had the mean age of onset of gout at the age of 49 years. ${ }^{30-32}$ Among the Nepalese gouty arthritic cases $21.3 \%$ were of $<30$ years of age. The trend to a younger onset of gouty arthritis among Nepalese and Indians with a similar socio-cultural background suggests some genetic predisposition in addition to purine rich meals, lack of exercise, decreased intake of water, or excessive alcohol consumption.

It has been reported that family history plays a positive role towards the development of gouty arthritis. ${ }^{27,30} \mathrm{Yu}$ et al found positive family history in $27.7 \%{ }^{29}$ and Chen SY et al in $44.3 \%{ }^{27}$ of their Taiwanese patients. We found positive family history in $22 \%$ of gout cases. Though lower than other studies, this finding supports that gout has familial predisposition and genetic inheritance. Interestingly, positive family history was found only in $3 \%$ of cases among South Indian gout cases. ${ }^{20}$

It has been said that the biologic precursor to gout is hyperuricaemia. ${ }^{8,25}$ The mean SUA level of the patients presenting with gouty attacks was $8.4 \pm 1.1 \mathrm{mg} / \mathrm{dL}$ while it was $7.2 \pm 0.7 \mathrm{mg} / \mathrm{dL}$ in case of asymptomatic hyperuricaemia. A similar level of SUA $(8.55 \mathrm{mg} / \mathrm{dL})$ was found in South Indian gout patients. ${ }^{20}$ Studies on Taiwanese patients ${ }^{28}$ and Japanese patients ${ }^{30}$ have shown a higher mean SUA level of $10.3 \mathrm{mg} / \mathrm{dL}$ and 
$10.1 \mathrm{mg} / \mathrm{dL}$ respectively. This finding suggests that the South Asian (Nepalese and Indian) population has a tendency to develop acute gout with a relatively lower level of SUA.

Recent scientific data illustrate that there is a link between diets with rheumatic disorders. Although gout is one of the better understood forms of rheumatic disorders, a number of management issues, including the role of dietary measures, remain uncertain. Being a metabolic disorder, gout is significantly influenced by dietary factors that lead to higher serum urate level. ${ }^{23-}$ 25,36 Overeating, a diet with a higher amount of meat and sea food, alcohol abuse and dyslipidemia, ${ }^{16,22,36}$ are said to be associated with a higher level of SUA, and, thus, often Gout is called a disease of kings or rich people. The findings of our study support this belief, as more than $95 \%$ of our cases were non-vegetarian, and in Nepal non-vegetarian food is more expensive than vegetarian food. On a Nepalese non-vegetarian food menu, preparations of internal organs of the animals are very common and are widely eaten. The internal organs of animals are said to be rich in purine content. Consumption of vegetable protein, vegetables (less in purine), fruits and dairy products has antihyperuricaemic effects. ${ }^{25}$ The number of vegetarians, those who had not eaten meat products for the last five years, was only eight in our study. However, the mean serum uric acid level was surprisingly almost the same in both the groups $(8.3 \mathrm{mg} / \mathrm{dL}$ in vegetarians and 8.4 $\mathrm{mg} / \mathrm{dL}$ in the non-vegetarian group). This may be due to the small number of vegetarian cases.

Alcohol drinking is one of the acknowledged risk factors for hyperuricaemia. There are many studies on the effects of alcohol drinking on SUA in Japanese populations. Shiraishi $\mathrm{H}$ et al ${ }^{37}$ have suggested that although combining the effects of obesity and drinking did not result in a multiplicative increase in the risk for hyperuricaemia, the combined risk was greater than the sum of the effects of obesity and drinking. Nishioka $\mathrm{K}$ et al ${ }^{41}$ studied the effects of different types of alcohol drinking on SUA and have concluded that at a moderate drinking level, beer and whisky have different effects on purine metabolism or excretion: beer consumption increases SUA and whisky does not. In our study, about $35 \%$ of the gout cases did not take alcohol and the others took alcohol. However, it was difficult to get proper information on the frequency, type and amount of alcohol consumption. In Nepal, alcohol consumption, though it depends on the ethnic group, is not socially well accepted among all communities. Therefore, the real number of alcohol drinking population might be higher than reported, particularly among the females. Moreover, home-made alcohol consumption is rampant, which is not found in other studies.

Increase in urine output can wash out SUA and it has been said that increase in the amount of daily water intake can lower the SUA level 10,38,40,42,43. In Nepal, people usually do not drink soft drinks and juices. Besides tea and dal soup, fluid intake is mostly plain water. The amount of water intake and its relation to the SUA was analyzed in this study. It showed that the mean SUA was inversely related to the amount of daily water intake. Gouty arthritic patients who took less than 1 liter of water had a $9.2 \mathrm{mg} / \mathrm{dL}$ mean SUA and it was $7.2 \mathrm{mg} / \mathrm{dL}$ in patients who drank more than 3 liters of water. This statistically significant $(p-0.0000)$ finding further strengthens the need to increase daily water intake to lower the SUA level.

The small sample size, a single hospital based study, and the short period of the study are the main limitations of this study. Therefore, the results of this study may not represent that of the whole Nepalese community. There was no control group and we did not correlate the serum uric acid level with the BMI of the gouty cases, which were also another limitations of the study. However, the findings do give some facts about hyperuricaemia and gout and may encourage more extensive community based studies.

\section{CONCLUSIONS}

Serum uric acid level was significantly high among the male gouty arthritic patients and also was relatively high among asymptomatic hyperuricaemic cases of both sexes. The findings further support and encourage the community to go for vegetarian food habits, plenty of daily water intake, and prohibition of alcohol and purine rich food to keep the SUA level within the normal limits.

\section{ACKNOWLEDGEMENTS}

We are thankful to the acute gout patients who spared their time to answer the questions in the forms. We thank all the staff of Department of Biochemistry for their help during the study. We express thanks to Prof. Chitra Kumar Gurung from the Institute of Medicine, Maharajgunj Campus for statistical analysis of the data.

\section{REFERENCES}

1. Nakamura T. Historical review of gout and hyperuricaemia investigations. Nippon Rinsho 2008;66:524-35.

2. Nuki G, Simkin PA. A concise history of gout and hyperuricemia and their treatment. Arthritis Res Ther 2006;8 Suppl 1:S1.
3. Saag KG, Choi H. Epidemiology, risk factor, and lifestyle modifications for gout. Arthritis Res Ther 2006;8 Suppl 1:S2.

4. Masseoud D, Rott K, Liu-Bryan R, Agudelo C. Overview of hyperuricaemia and gout. Curr Pharm Des 2005;11:4117-24. 
5. Bieber, J.D; Terkeltaub, R.A. Gout: on the brink of novel therapeutic options for an ancient disease. Arthritis Rheum 2004;50:2400-14.

6. Harris MD, Siegel LB, Alloway JA. Gout and hyperuricaemia. Am Fam Physician 1999; 59(4):925-34

7. Li EK. Gout: A review of its aetiology and treatment. Hong Kong Med J. 2004;10(4):261-70.

8. Eggebeen AT. Gout: An update. Am Fam Physician. 2007;76(6):801-8.

9. Ene-Stroescu D, Gorbien MJ. Gouty arthritis. A primer on late onset gout. Geriatrics. 2005;60:24-31.

10. Puig JG, Martínez MA. Hyperuricaemia, gout and the metabolic syndrome. Curr Opin Rheumatol 2008;20:187-91.

11. Mikuls TR, Saag KG. New insights into gout epidemiology. Curr Opin Rheumatol 2006;18:199-203.

12. Andrew J. Luk Epidemiology of Hyperuricaemia and Gout. Am J Manag Care.2005;11:S435-42.

13. Magliano M. Obesity and arthritis. Menopause Int. 2008;14:149-54

14. Weaver AL. Epidemiology of gout. Cleve Clin J Med. 2008;75:S9-12.

15. Klemp, P; Stansfield, S.A; Castle, B; Robertson, M.C. Gout is on the increase in New Zealand. Ann Rheum. Dis. 1997; $56: 22-6$.

16. Rose BS. Gout in Maoris. Semin Arthritis Rheum. 1975;5:12145 .

17. Conen D, Wietlisbach V, Bovet P, Shamlaye C, Riesen W, Paccaud F, et. al. Prevalence of hyperuricemia and relation of serum uric acid with cardiovascular risk factors in a developing country. BMC Public Health. 2004;25:4-9.

18. Nan H, Qiao Q, Dong Y, Gao W, Tang B, Qian R, et.al. The prevalence of hyperuricemia in a population of the coastal city of Qingdao, China. J Rheumato 2006;33:1346-50.

19. Hakoda M. Epidemiology of hyperuricemia and gout in Japan. Nippon Rinsho 2008;66:647-52.

20. Porkodi R, Parthivan M, Rukmangatharajan S, Kamakarani P, Pancha Pakisa Rajendaran C. Clinical spectrum of gout in South India. J Indian Rheumatology Association 2002;10: 61-65.

21. So A. Development in the scientific and clinical understanding of gout. Arthritis Res Ther 2008;10:221.

22. Lin KC, Lin HY, Chou P. The interaction between uric acid level and other risk factors on the development of gout among asymptomatic hyperuricemic men in a prospective study. J Rheumatol 2000;27:1501-5.

23. Benecke M. Avoid purine-rich foods, drink a lot, reduce weight. The most important recipes against hyperuricemia. MMW Fortschr Med 2003; 7:36-8.

24. Yu KH, See LC, Huang YC, Yang CH, Sun JH. Dietary factors associated with hyperuricaemia in adults; Semin Arthritis Rheum 2008;37:243-50.

25. Schlesinger N. Dietary factors and hyperuricaemia. Curr Pharm Des 2005;11:4133-8.

26. Miao Z, Li C, Chen Y, Zhao S, Wang Y, Wang Z, et.al. Dietary and lifestyle changes associated with prevalence of hyperuricaemia and gout in the Shandong coastal cities of Eastern China; J Rheumatol 2008;35:1859-64.

27. Chen SY, Chen CL, Shen ML, Kamatani N. Clinical features of familial gout and effects of probable genetic association between gout and its related disorders. Metabolism 2001;50:1203-7.

28. Yu GH, Chen JY, Wu Y-JJ, Ho HH, Luo SF. Clinical features of 1226 gout patients. J Intern Med ROC 1993; 4:226.

29. Yu, K.H and Luo, S.F. Younger age of onset of gout in Taiwan. Rheumatology 2003;42:166-170.

30. Nishioka, N. and Mikangi, K. Clinical features of 4000 gouty subjects in Japan. Adv. Exp. Med. Biol 1980;122A: 47-54.

31. Hall, A.P; Barry, P.E; Dawber, T.R; McNamara, P.M Epidemiology of gout and hyperuricaemia; a long term population study. Am. J. Med 1967;42:27-37.

32. Meigs JB, Wilson PW, Nathan DM, D'Agostino RB Sr, Williams K, Haffner SM. Prevalence and characteristics of the metabolic syndrome in the San Antonio Heart and Framingham Offspring Studies. Diabetes 2003;52:2160-67.

33. Dehghan A, Köttgen A, Yang Q, Hwang SJ, Kao WL, Rivadeneira F, et al. Association of three genetic loci with uric acid concentration and risk of gout: a genome-wide association study. Lancet 2008;372:1953-61.

34. Bleyer AJ, Hart TC. Genetic factors associated with gout and hyperuricaemia. Adv Chronic Kidney Dis 2006;13:124-30.

35. Koga M, Saito H, Mukai M, Kasayama S, Yamamoto T. Factors contributing to increased serum urate in postmenopausal Japanese females. Climacteric 2009;12:146-52.

36. Choi HK, Liu S, Curhan G. Intake of purine-rich foods, protein, and dairy products and relationship to serum levels of uric acid: the third national health and nutrition examination survey. Arthritis Rheum 2005;52:283-9.

37. Shiraishi $\mathrm{H}$, Une $\mathrm{H}$. The effect of the interaction between obesity and drinking on hyperuricaemia in Japanese male office workers. J Epidemiol 2009;19:12-6.

38. Choi HK, Curhan G. Coffee, tea, and caffeine consumption and serum uric acid level: the 3 rd the third national health and nutrition examination survey. Arthritis Rheum 2007;57:81621

39. Choi, H.K. Dietary risk factors for rheumatic disease. Curr Opin Rheumatol 2005;17:141-6.

40. Choi JW, Ford ES, Gao X, Choi HK. Sugar-sweetened soft drinks, diet soft drinks, and serum uric acid level: the Third National Health and Nutrition Examination Survey. Arthritis Rheum 2008;59:109-16.

41. Nishioka K, Sumida T, Iwatani M, Kusumoto A, Ishikura $\mathrm{Y}$, Hatanaka $\mathrm{H}$, et al. Influence of moderate drinking on purine and carbohydrate metabolism. Alcohol Clin Exp Res 2002;26:S20-25.

42. Borghi L, Meschi T, Amato F, Briganti A, Novarini A, Giannini A. Urinary volume, water and recurrences in idiopathic calcium nephrolithiasis: a 5-year randomized prospective study. J Urol 1996;155:839-43.

43. Meschi T, Schianchi T, Ridolo E, Adorni G, Allegri F, Guerra A, et al. Body weight, diet and water intake in preventing stone disease. Urol Int 2004;72:S29-33. 